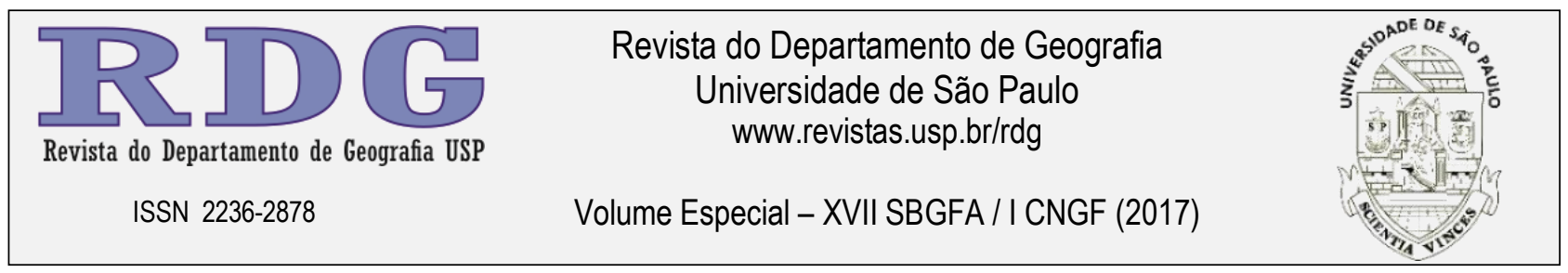

\title{
Relato de Experiência Desenvolvida com Estudantes da NEJA no Ensino de Climatologia em Baixa Grande - Campos Dos Goytacazes/RJ
}

\section{Report on Experience Developed with NEJA Students in Climatology Education in Baixa Grande - Campos Dos Goytacazes/RJ}

\author{
Taísa das Dores Pereira \\ Universidade Federal Fluminense \\ taisaddp@id.uff.br \\ Maria do Socorro Bezerra de Lima \\ Universidade Federal Fluminense \\ sblima22@gmail.com
}

Maria Gertrudes Alvarez Justi da Silva
Universidade

Universidade Estadual do Norte Fluminense Darcy Ribeiro

justi.meteoro@gmail.com

Resumo: O ensino de climatologia faz parte do currículo de geografia e é apresentado demonstrando a relação que há entre a superfície terrestre e a atmosfera. $\mathrm{O}$ ensino de climatologia estuda a dinâmica, a classificação e a descrição do clima, a ocorrência de fenômenos na atmosfera e sua influência na sociedade. Sua importância se dá à medida que contribui para o desenvolvimento de habilidades fundamentais para o processo de ensino aprendizagem. Este estudo tem como principal objetivo trabalhar o fenômeno meteorológico chuva, através dos conteúdos de aprendizagens nas aulas de geografia da Nova Educação de Jovens e Adultos. As atividades realizadas ocorreram no Colégio Estadual Dr. Barros Barreto, na localidade de Baixa Grande, no município de Campos dos Goytacazes/RJ. Os procedimentos operacionais compreenderam a instalação de uma estação meteorológica móvel na escola, o monitoramento do tempo e o desenvolvimento de atividades e experiências pedagógicas. Os resultados apontam para a defasagem no ensino de disciplinas essenciais, a dificuldade dos alunos de se expressar através da escrita, e a percepção de que é viável utilizar os conteúdos de aprendizagens no ensino de climatologia. Assim, é possível concluir que a valorização dos saberes e os conteúdos de aprendizagens corroboram e auxiliam o processo no ensino de climatologia nas aulas de Geografia.

Palavras-chave: Educação; Geografia Escolar; Fenômenos Meteorológicos; EJA.

\begin{abstract}
The teaching of climatology is part of the geography curriculum and it's presented showing the relationship between the Earth's surface and the atmosphere. The teaching of climatology studies the dynamics, the grading and the description of the climate, the occurrence of phenomena in the atmosphere and its influence in the society. Its significance is given because it contributes to the development of essentials skills for the process of teaching and learning. The study has its main aim the meteorological phenomenon rain, about the content of learning in the geography classes of the New Education of Youths and Adults. The activities executed took place at the Barros Barreto State College, in the town of Baixa Grande, in the municipality of Campos dos Goytacazes/RJ. The operational procedures included the installation and monitoring of a mobile weather station in the school and the development of pedagogical activities and experiences. The results point to the lag in teaching of the essential subjects, to the difficulties of students to express through writing, and that it's possible to use the contents of learning in climatology teaching. Therefore, it is possible to conclude that the valorization of knowledge and learning contents confirm and also help during the learning process in teaching climatology in Geography classes.
\end{abstract}

Keywords: Education; School Geography; Meteorological Phenomena; EJA. 


\section{INTRODUÇÃO}

Na disciplina de geografia, o conteúdo de climatologia faz parte do currículo mínimo e é apresentado demostrando a importância que há entre a superfície terrestre e a atmosfera, a diferenciação entre tempo e clima e de como suas dinâmicas relações acabam influenciando diretamente a sociedade. $\mathrm{O}$ ensino de climatologia é importante porque o tempo e o clima estão presentes no cotidiano dos alunos, seja através da observação em relação ao tempo e a temperatura diária, seja pelos noticiários com boletins e previsões do tempo, divulgados pelos diferentes meios de comunicação. Além disso, o ensino de climatologia também vai contribuir para que o aluno desenvolva habilidades como interpretação, compreensão, observação e leitura de mundo na geografia.

O presente trabalho trata dos fenômenos meteorológicos, com enfoque na chuva, que nos livros didáticos é um tema que nem sempre é abordado, e quando o é, aparece de forma superficial, associado a classificações específicas ou a catástrofes naturais. Dada à importância que os fenômenos meteorológicos têm e sua influência no dia a dia da sociedade, busca-se valorizar o conhecimento prévio dos estudantes, o saber popular, e articulá-lo com o saber científico. Na tentativa de tornar o ensino de climatologia mais prazeroso, o trabalho desenvolvido utilizou em sala de aula os conteúdos de aprendizagens propostos por Zabala (1998) que consistem nos seguintes conteúdos: conceitual, procedimental e atitudinal.

O estudo tem como principal objetivo trabalhar o fenômeno meteorológico chuva (precipitação) através dos conteúdos de aprendizagem nas aulas de geografia da Nova Educação de Jovens e Adultos NEJA. A pesquisa foi aplicada com a turma da NEJA III do turno noturno, do Colégio Estadual Doutor Barros Barreto, que se encontra na localidade de Baixa Grande, no $5^{\circ}$ distrito de Mussurepe, no município de Campos dos Goytacazes, Região Norte Fluminense do estado do Rio de Janeiro, no período compreendido entre novembro e dezembro de 2015. Os resultados apresentados neste trabalho expressam às conclusões obtidas a partir do Trabalho de Conclusão de Curso de Licenciatura em Geografia pela Universidade Federal Fluminense.

\section{A CHUVA NO ENSINO DE CLIMATOLOGIA}

$\mathrm{Na}$ geografia, o ensino do conteúdo de climatologia é muito importante para que os estudantes possam desenvolver habilidades como assimilar, observar e interpretar os fenômenos que ocorrem diariamente na atmosfera. Por isso, aprender a diferença entre tempo e clima, a composição e os processos que ocorrem na atmosfera, suas classificações e atuação são fatores que compreende o ensino de climatologia.

É na atmosfera que acontecem os fenômenos de ordem meteorológica. Os fenômenos são "quaisquer fatos que possam ser descritos cientificamente" (ANTAS, 1979, p.322) e que venham a ocorrer na atmosfera. Por fenômeno meteorológico entende-se que são manifestações momentâneas, temporais e relacionados com o tempo meteorológico que acontecem na troposfera, de acordo com Ahrens (1993). Existem três fatores importantes para sua ocorrência: "1. Alta porcentagem de vapor d'água; 2. Presença de núcleos de condensação [...]; 3. Aquecimento e resfriamento por radiação" (SONNEMAKER, 2011/2012, p.18).

A chuva é um fenômeno meteorológico classificado como hidrometeoro. De acordo com VarejãoSilva (2006), os hidrometeoros são manifestações compostas por partículas de natureza hídrica, que ocorrem tanto no estado líquido ou sólido, na atmosfera em direção à superfície terrestre. A chuva pode acontecer na forma de precipitação líquida na natureza, ou seja, quando o vapor d'água se condensa nas nuvens e se precipita na forma de gotas (ANTAS, 1979).

Sua distribuição no planeta não é homogênea variando de acordo com a geografia dos lugares. A disposição das chuvas na Terra está diretamente associada a circulação atmosférica, "as correntes marítimas, os ventos oceânicos e a dinâmica da baixa atmosfera" (MENDONÇA; DANNI-OLIVEIRA, 2007, p.72).

Outro aspecto importante é o monitoramento que é realizado por diversos instrumentos meteorológicos afim de, acompanhar o comportamento diário do tempo e do clima pelo mundo. São utilizados para mensurar dados de pluviosidade o pluviômetro, o pluviógrafo e o radar meteorológico, entre outros. No caso das chuvas, estes instrumentos são responsáveis pela obtenção de dados como frequência, duração e intensidade da mesma. Possuem um papel de grande relevância para a sociedade ao monitorar este fenômeno. 
A chuva é fundamental para a sobrevivência dos seres vivos na Terra, ela contribui para a manutenção do ciclo hidrológico, ajuda a regular a temperatura, abastece corpos hídricos, além de sua importância para diversos tipos de atividades essenciais para a sociedade. A chuva foi o fenômeno meteorológico escolhido para o desenvolvimento de atividades com os estudantes da NEJA. Devido a sua importância, fez-se necessário que os alunos tivessem conhecimento deste fenômeno.

\section{O ENSINO DE CLIMATOLOGIA NA EDUCAÇÃO DE JOVENS E ADULTOS}

A geografia como disciplina, deve possibilitar ao estudante interpretar, observar, compreender e formar seu próprio sentido de mundo, podendo assim cotejar seu universo cotidiano com o conhecimento adquirido na escola (PEREIRA, 2016). De acordo com Callai (2005), é indispensável valorizar as vivências dos alunos e articular com o conhecimento aprendido na escola, assim o ensino de geografia e o conteúdo de climatologia tornam-se mais interessantes.

O conteúdo de climatologia faz parte do currículo mínimo de geografia da NEJA, todavia é um assunto que não é abordado nos Parâmetros Curriculares Nacionais. No currículo mínimo do estado do Rio de Janeiro, a climatologia aparece de forma superficial e fragmentada (PEREIRA, 2016). A climatologia está contida na área de geografia física que no módulo III da NEJA, é apresentado juntamente com indústria, sociedade em rede, questão energética e crise ambiental. Vale ressaltar, que o professor possui um semestre para ensinar todos estes conteúdos, tempo relativo a cada módulo, dentro de sala de aula.

Ao trabalhar o ensino de climatologia na Educação de Jovens e Adultos, o professor e a escola tem que levar em consideração o conhecimento que o aluno já possui, conhecimento este, que advém de experiências que deveriam ser valorizados e articulados com o saber produzido na escola. Porém, a escola na maioria das vezes acaba não dando importância ou mesmo desprezando estas formas de saberes. Se houvesse um diálogo da escola com outras formas de saber seria "possível investigar e valorizar os conhecimentos prévios dos alunos, com a intenção de construir conhecimentos mais elaborados - o conhecimento científico" (KOVALSKI et al., 2012, p.5)

Além da importância do conhecimento prévio desses alunos, existem outras formas que colaboram como mecanismos para tornar o ensino de climatologia mais interessante e prazeroso. $\mathrm{O}$ ato de utilizar outros recursos para além do livro didático, como as Novas Tecnologias de Informação e Comunicação (NTICs) vai possibilitar "[...] o uso de diferentes formas de linguagem e expressão" (FORTUNA, 2012, p.77). Utilizar sites (INPE, CPTEC, Google Earth), vídeos, músicas, fotografias, desenhos, estação meteorológica, jornais, entre outros instrumentos, são recursos preciosos, que uma vez trabalhados podem estabelecer uma aproximação com a realidade dos alunos. Assim os estudantes têm mais facilidade em assimilar e relacionar a climatologia com o espaço geográfico e construir sua própria leitura de mundo, vindo daí a importância do professor como mediador. O professor ao mediar o conteúdo de climatologia com as vivências e o contexto social no qual este aluno está inserido proporcionando que o conteúdo ultrapasse os muros da escola e adentre a sala de aula, viabilizando assim, uma afinidade entre aprendizagem e realidade do aluno (SOUZA; OLIVEIRA, 2012).

\section{OS CONTEÚDOS DE APRENDIZAGEM}

Valorizar os conhecimentos prévios e adaptá-los ou adequá-los a um novo conteúdo facilitará um melhor aprendizado. Os alunos têm seu primeiro contato com a climatologia nas vivências do dia a dia, com os saberes que lhes são ensinados em casa e pelos meios de comunicação, logo há importância de se reconhecer esta forma de conhecimento. Segundo Zabala (1998), por mais específico que o conteúdo seja, ele sempre será aprendido em conjunto com outros conteúdos, passando a ganhar formato durante o processo de aprendizagem. Este processo deve permitir e proporcionar capacidades e habilidades que contribua não só com a formação do aluno dentro de sala, mas para além dos muros da escola, tornando-o um cidadão crítico em relação a si e a sociedade.

Zabala (1998) propõem tipologias que auxiliam no aprendizado que são os conteúdos de aprendizagem. Os conteúdos de aprendizagem podem ser divididos em: factuais, conceituais, procedimentais e atitudinais. Os conteúdos factuais são conhecimentos relacionados a fatos e acontecimentos. É um tipo de conhecimento onde o estudante sabe ou não sabe, estando muito conectado ao ato de memorizar, de lembrar 
ou recordar de algo. O conteúdo factual deve ser trabalhado junto com o conteúdo conceitual, pois suplementa o conceitual (NERVIS et al., 2012). O conteúdo conceitual trabalha com conceitos e princípios, palavras que se complementam para dar forma ao mesmo. Este conteúdo é a base para que o aluno possa compreender e entender o significado das coisas. Por exemplo: definir o que é tempo e o que é clima. Os conteúdos procedimentais são um conjunto de ações com finalidade dirigida para a realização de um objetivo (ZABALA, 1998). Esses atos ou habilidades podem ser: correr, ler, brincar, jogar, exercitar, cantar, recortar, etc. Feitos que de forma gradativa compõem processos que contribuem com o desenvolvimento da aprendizagem do aluno. Por exemplo: construir uma estação meteorológica, produzir e interpretar climogramas. Por fim, os conteúdos atitudinais agrupam os valores, atitudes e normas relacionadas com o posicionamento do indivíduo ou coletivo sobre a forma de ler o mundo (ZABALA, 1998). Por exemplo: pedir a opinião do aluno sobre como o clima afeta a sociedade.

Segundo Nervis et al. (2012) normalmente os conteúdos atitudinais e procedimentais vão sendo desenvolvidos e trabalhados nas séries iniciais e os conteúdos conceituais ao longo do tempo, conforme a progressão nos níveis de escolarização. No fim, os conteúdos de aprendizagem interagem, complementandose como mecanismos que visam auxiliar no processo de ensino-aprendizagem da formação do aluno.

\section{MATERIAIS E MÉTODOS}

O estudo foi desenvolvido no Colégio Estadual Doutor Barros Barreto, na localidade de Baixa Grande, no $5^{\circ}$ distrito de Mussurepe, no município de Campos dos Goytacazes/RJ. O projeto foi desenvolvido com os alunos da NEJA III, por trabalhar o conteúdo de climatologia. A elaboração das atividades realizadas neste trabalho compreende o período de 12 de novembro a 14 de dezembro de 2015 , período em que a estação meteorológica ficou instalada na escola. A turma da NEJA III contava com 16 alunos que participaram das atividades. A escolha da escola se deu através da necessidade de efetuar uma prática diferenciada sobre fenômenos meteorológicos com a finalidade de acrescentar e contribuir com o ensino de geografia na NEJA.

Os procedimentos metodológicos podem ser divididos em: Projeto FAPERJ; Levantamento bibliográfico; Levantamento documental; Levantamento de dados; Visita a área de estudo (a escola); Instalação da estação meteorológica móvel; Elaboração das atividades; Aplicação das atividades; Análise e síntese dos resultados.

Projeto FAPERJ: O presente trabalho teve como base o Projeto de Iniciação Científica da Fundação de Amparo à Pesquisa do Estado do Rio de Janeiro - FAPERJ, que vigorou do período de abril de 2014 a março de 2015. A iniciação científica se inseria em um projeto intitulado "Tempo de aprender em clima de ensinar" que teve como principal objetivo incentivar a melhoria do ensino através da inserção da meteorologia nas escolas públicas. O projeto foi desenvolvido no Colégio Estadual Rachel Reid de Souza, localizado no município de Macaé, na região Norte Fluminense do estado do Rio de Janeiro. A pesquisa foi coordenada pela professora Maria Gertrudes Alvarez Justi da Silva, professora da Universidade Estadual do Norte do Rio de Janeiro Darcy Ribeiro (UENF) do Laboratório de Meteorologia. Dentre as práticas empreendidas durante o projeto, teve a instalação de uma estação meteorológica móvel, para incentivar o monitoramento e observação do tempo. A estação meteorológica móvel teve grande valor para a realização do projeto e também para o desenvolvimento das atividades que corroborou para um Trabalho de Conclusão de Curso desenvolvido pela primeira autora. A estação foi emprestada temporariamente e foi instalada no Colégio Estadual Dr. Barros Barreto, no município de Campos dos Goytacazes por um mês, período que compreendia as práticas da monografia.

Levantamento bibliográfico, documental e de dados: consistiu na pesquisa de livros, artigos, documentos e dados oficiais que serviram para ser a base estrutural de realização da monografia. Foi de suma importância para ajudar a entender e compreender as temáticas tratadas na pesquisa.

Visita à área de estudo (a escola): antes de realizar as atividades, foram feitas visitas a escola a fim de estabelecer um vínculo com a direção, conhecer previamente a turma e conversar com os professores. Foi possível assim, dar início a um vínculo para o desenvolvimento das práticas.

Instalação da estação meteorológica móvel: a estação meteorológica móvel (Figura 1) é o Dispositivo Remoto de Informações Agrometeorológicas (DRIA-0111), que mede em tempo real o que está ocorrendo no tempo. A DRIA-0111 é composta por: um monitor LCD com sensores internos de temperatura, umidade e pressão atmosfera captados através do receptor wireless; um transmissor eletrônico de dados; um pluviômetro; um anemômetro; um sensor de direção do vento; um termo-higrômetro e um painel solar. 
Através dos instrumentos é possível aferir dados de temperatura interna e externa, de precipitação (chuva), de pressão atmosférica, de direção e velocidade do vento, de umidade relativa do ar interna e externa, de radiação solar e índice de ultravioleta (UV). Os dados foram coletados diariamente, em intervalos de 15 minutos, podendo ser visualizados também pela internet.

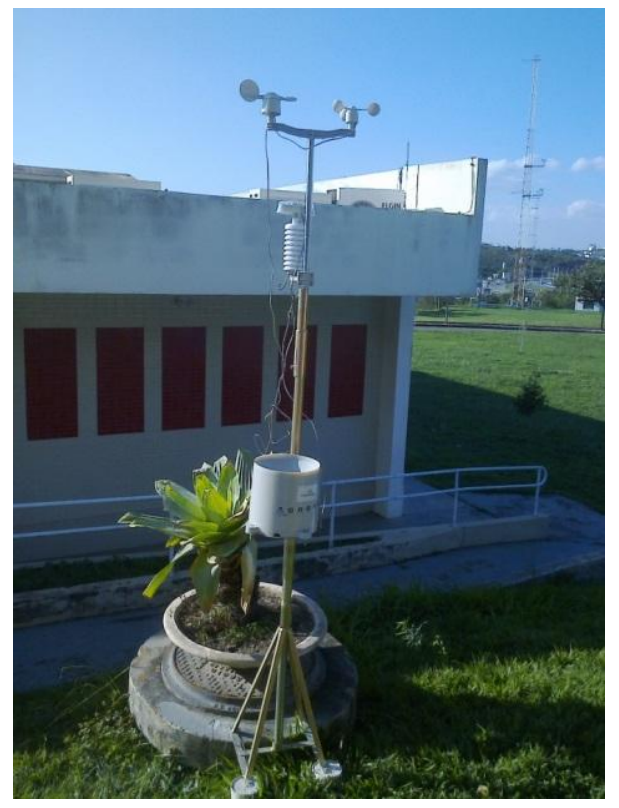

Figura 1: Estação meteorológica móvel. Fonte: Acervo pessoal (2015).

Elaboração das atividades: foram realizados planos de aula e produzidos materiais pedagógicos como: folder informativo, textos de apoio, quadro de observação do tempo, exercício, quadro de dados coletados pela estação. Foram efetuadas sete atividades: estação meteorológica móvel; quadro de observação do tempo; exercício de comparação entre o quadro de observação do tempo e o quadro de dados obtidos pela estação meteorológica móvel; exercício de fixação; dinâmica da caixa; construção dos gráficos e autoavaliação.

Aplicação das atividades: As atividades da monografia foram realizadas durante três dias letivos sendo eles: 17 de novembro, 24 de novembro e 01 de dezembro de 2015.

No primeiro dia: Trabalhou-se com os conteúdos de clima, tempo, atmosfera e estação meteorológica. Tendo como objetivos: Diferenciar tempo e clima; Conhecer o que é atmosfera e sua estratificação; Entender o que é uma estação meteorológica; Apresentar quais são os instrumentos meteorológicos e suas funções; Analisar a importância da estação meteorológica no seu dia a dia e no ensino de geografia.

No segundo dia: Foram apresentados os conteúdos de precipitação e ciclo hidrológico. Os principais objetivos deste dia eram: Entender a dinâmica do ciclo hidrológico e os principais agentes que o compõem; Compreender o que é precipitação e sua classificação.

No terceiro dia: Aplicação de oficina, contendo tudo que foi abordado ao longo daqueles dias, com foco em chuva. Foi realizada a dinâmica da caixa, a construção de gráficos a partir dos dados obtidos pela estação meteorológica e, por fim, questões avaliativas. Neste dia, os principais objetivos consistiam em entender e identificar a importância dos saberes populares sobre chuva e construir e interpretar gráficos a partir dos dados de pluviosidade.

\section{RESULTADOS E DISCUSSÕES}

Estação meteorológica móvel: Através da estação meteorológica os alunos aprenderam sobre os instrumentos meteorológicos, sua função, coleta, monitoramento e análise de dados. Com esta prática foram alcançados todos os conteúdos de aprendizagem, além de possibilitar o desenvolvimento de habilidades como: percepção, observação, análise e interpretação. 
Os estudantes conseguiram associar e entender os conceitos básicos apresentados em sala de aula, manuseando, observando e descrevendo os instrumentos meteorológicos presentes na estação, alcançando principalmente o conteúdo conceitual e também o procedimental (Figura 2). O conteúdo atitudinal foi alcançado, pois os estudantes foram capazes de expressar e manifestar suas opiniões sobre a importância e a diferença que uma estação pode ter para a sociedade.

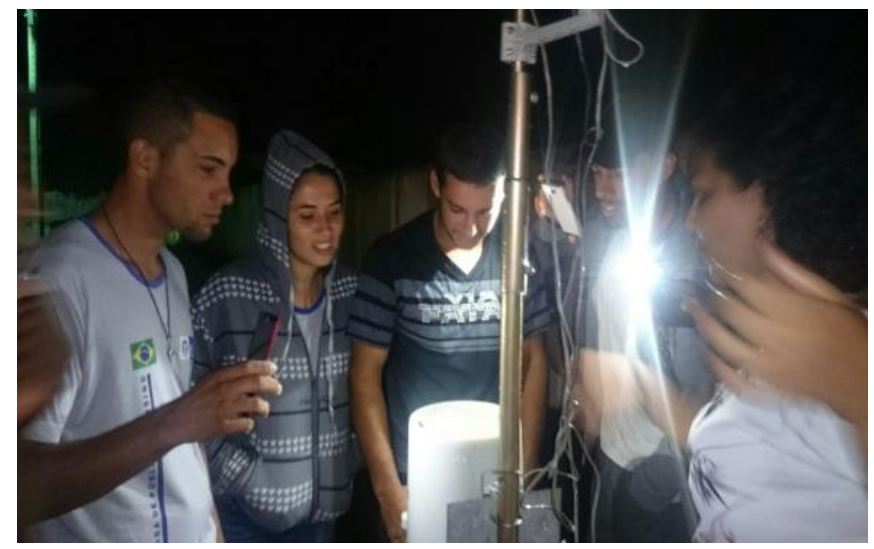

Figura 2: Momento em que os alunos conhecem a estação meteorológica móvel. Fonte: Pesquisa de campo (2015).

O quadro de observação do tempo: Consistiu na observação do tempo durante uma semana. Os estudantes deveriam observar o tempo no decorrer dos turnos (manhã, tarde e noite), podendo desenhar o símbolo ou apontar a letra referente a descrição contida na legenda. Dois conteúdos de aprendizagem foram trabalhados neste exercício, o conceitual e o procedimental. Esta prática também propiciou habilidades como: observação, descrição, interpretação e monitoramento.

A partir do momento em que os alunos foram colocados para observar, descrever ou desenhar e interpretar o tempo trabalhou-se o conteúdo procedimental. O conteúdo conceitual foi alcançado no momento em que os estudantes foram capazes assimilar o conceito de tempo e assim perceber o quanto o tempo é momentâneo, através do ato de observação. Vale ressaltar que $80 \%$ da turma realizou a atividade.

Exercício de comparação entre o quadro de observação do tempo e o quadro de dados obtidos pela estação: Nesta prática a atividade baseia-se no ato de comparar e descrever os principais pontos observados, a partir dos dados coletados pela estação na escola em comparação com o quadro de observação do aluno. Nesta atividade foram alcançados todos os conteúdos de aprendizagem e as seguintes habilidades: observação, descrição, comparação, interpretação e escrita.

O conteúdo conceitual foi desenvolvido durante toda a prática, juntamente com o entendimento do conceito de tempo, aspecto positivo desta atividade. Mesmo aqueles alunos que não fizeram o exercício anterior, participaram com as suas recordações sobre o tempo ao longo daquela semana. Do mesmo modo que o conteúdo conceitual, o procedimental também foi realizado durante toda a atividade, pois os estudantes além de observarem e descreverem o tempo tiveram que comparar e descrever suas percepções. $\mathrm{O}$ ato de interpretar e expressar suas opiniões possibilitou o alcance do conteúdo atitudinal. Observação: no decurso desta prática, notou-se que os alunos tinham facilidade de expor suas opiniões oralmente, mas uma grande dificuldade de expressá-las pela escrita.

Exercício de fixação: esta atividade visava avaliar se os alunos haviam conseguido assimilar e compreender os conteúdos apresentados e explicados. O exercício era composto por cinco questões que propiciaram desenvolver habilidades como: leitura, escrita, concentração, interpretação e expressão.

O conteúdo conceitual era indispensável para o desenvolvimento desta atividade, servindo para perceber se os alunos conseguiram entender os conceitos apresentados. Todas as ações que os estudantes tiveram que empregar para efetuar o exercício, como leitura, escrita e concentração possibilitou o conteúdo procedimental. O conteúdo atitudinal foi obtido, através da realização de duas questões individuais, onde o aluno tinha que expressar sua opinião. Observação: a maior parte das respostas individuais estava relacionada com a realidade que lhes é muito próxima ou ao modo de vida em que estes alunos estão inseridos. Observou-se através do exercício que alguns conceitos não foram bem assimilados, tais como: o ciclo hidrológico (escoamento superficial e evapotranspiração) e a função dos instrumentos meteorológicos.

Dinâmica da caixa: Esta dinâmica buscava trabalhar e resgatar a importância dos saberes populares, relacionando-os com os saberes científicos. A caixa continha alguns saberes populares sobre chuva como: 
simpatias, ditos populares, lendas e santinhos que foram apresentados aos estudantes. Partindo do pressuposto de que alguns conhecimentos são transmitidos pela oralidade e hereditariedade, cada aluno deveria resgatar em sua memória algum saber popular que lhe fora ensinado sobre chuva. $\mathrm{O}$ estudante deveria escrever num papel, contribuindo assim, com um novo saber popular para a caixa e depois deveria compartilhar seus conhecimentos com a turma. Isto possibilitou que o aluno desenvolvesse habilidades como: observar, escrever, relacionar e compartilhar, adquirindo assim todos os conteúdos de aprendizagens.

O conteúdo conceitual foi trabalhado a todo o momento, pois previamente os estudantes já tinham noção do conceito de chuva e tempo, isso passou a facilitar a relação entre conhecimento popular e o conhecimento científico. O conteúdo procedimental foi desenvolvido através do exercício da oralidade, da escrita, e também pela capacidade de relacionar e articular os conceitos. O conteúdo atitudinal teve grande destaque nesta atividade, pois os alunos puderam falar sobre a chuva a partir de suas vivências e do conhecimento que lhes foram transmitidos ao longo da vida. Principalmente expressar suas relações, atitudes e valores pessoais. Observação: durante a elaboração desta prática, a pesquisadora foi surpreendida por posicionamentos que os estudantes tinham sobre determinada forma de saber popular. Quando o item simpatia foi abordado, muitos alunos não o enxergavam como uma forma de saber, chegando a demonstrar um elevado grau de intolerância religiosa. Os estudantes associavam simpatia com as religiões de matrizes africanas, chamando a atenção, a forma negativa como viam estas religiões. Durante esta atividade foi preciso parar a dinâmica por um tempo e explicar sobre o tema, sua importância e contribuição na formação da cultura popular. Outro ponto notável foi o diálogo entre saber popular e o saber científico dentro da escola e na produção de conhecimento.

Construção dos gráficos: a atividade consistia na criação e interpretação de gráficos a partir dos dados coletados pela estação meteorológica na escola (Figura 3). Utilizou-se 16 dias de dados que foram divididos entre quatro grupos de alunos. Ao término da elaboração dos gráficos, os mesmos foram colocados lado a lado na lousa e os estudantes puderam comparar e analisar como foi o tempo ao longo daqueles dias. A prática possibilitou desenvolver habilidades como: ler, interpretar, comparar, escrever, construir, analisar, verificar e trabalhar em equipe. Todos os conteúdos de aprendizagem foram contemplados.

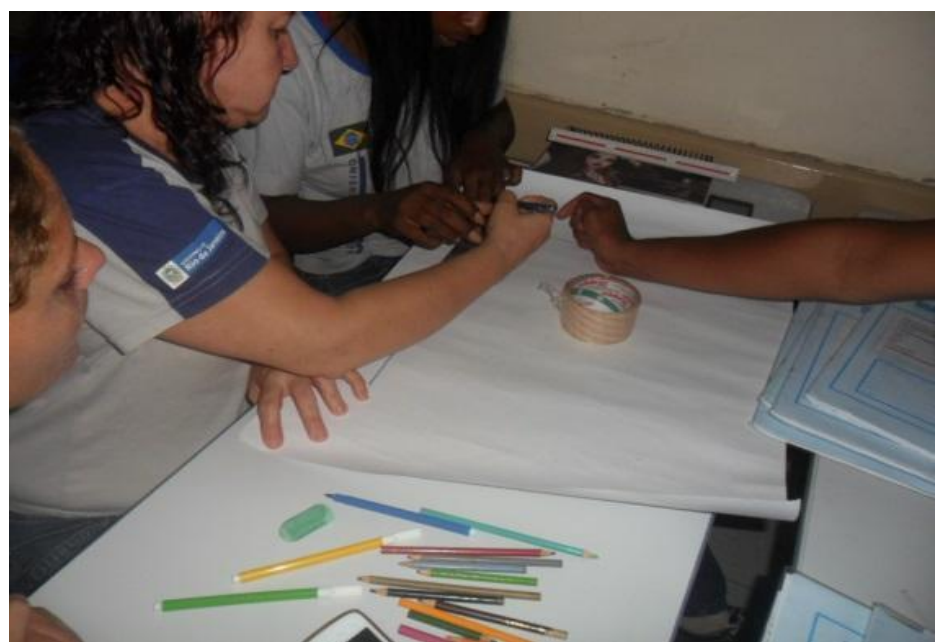

Figura 3: Elaboração dos gráficos com os índices de precipitação. Fonte: Pesquisa de campo (2015).

O ato de construírem o gráfico, de interpretar e comparar assim como, o fato de trabalharem em equipe e interagirem, colaborou para alcançar os conteúdos procedimentais e atitudinais. $\mathrm{O}$ aluno ao saber explicar os dados, relatar a ocorrência de chuvas ao longo dos dias, demonstrar compreensão e entendimento de alguns conceitos, alcançou o conteúdo conceitual. Observação: os estudantes apresentaram dificuldade em como fazer e ler o gráfico, demonstrando assim defasagem em matemática, pré-requisito para realização desta prática. Esta atividade foi a mais produtiva, pois todos os alunos interagiram entre si, trabalhando em equipe para a elaboração dos gráficos.

Autoavaliação: Averiguar e avaliar através de perguntas o que os alunos acharam das atividades realizadas. Nesta prática, somente o conteúdo atitudinal foi alcançado, todavia também possibilitou ao estudante se expressar, interpretar e explicar, gerando assim, habilidades. 
Através da percepção, os estudantes expressaram suas opiniões e críticas contribuindo com o conteúdo atitudinal. Observação: Avaliando de forma geral, todos gostaram das práticas e do conteúdo, apesar de manifestarem dificuldades em determinados aspectos. Destaca-se a sinceridade dos alunos em se dar uma nota, avaliando sua participação e desempenho ao longo das atividades.

No Quadro 1 é apresentado a síntese da avaliação dos conteúdos de aprendizagem classificadas sobre a perspectiva da investigação durante o desenvolvimento de cada atividade.

Quadro 1 - Classificação e avaliação dos Conteúdos de Aprendizagem

\begin{tabular}{|l|c|c|c|}
\hline \multirow{2}{*}{\multicolumn{1}{|c|}{ Atividades }} & \multicolumn{3}{c|}{ Conteúdos de Aprendizagem } \\
\cline { 2 - 4 } & Conceitual & Procedimental & Atitudinal \\
\hline Estação meteorológica móvel & Regular & Bom & Regular \\
\hline Quadro de observação do tempo & Regular & Bom & - \\
\hline Exercício de comparação & Bom & Bom & Bom \\
\hline Exercício de fixação & Regular & Bom & Regular \\
\hline Dinâmica da caixa & Regular & Bom & Bom \\
\hline Construção dos gráficos & Bom & Bom & Bom \\
\hline Autoavaliação & - & - & Regular \\
\hline
\end{tabular}

Fonte: Elaboração própria baseada em ZABALA (1998)

Nenhuma das práticas foi avaliada como ruim, pois considerou-se que é possível utilizar os conteúdos de aprendizagem em sala de aula, apesar de complexos. As atividades classificadas como "regular", foram principalmente por perceber que os alunos tiveram dificuldades com determinadas práticas e conteúdos e, porque de alguma forma, não conseguirem alcançar o que foi proposto. As atividades classificadas como "bom" foram aquelas onde se conseguiu sucesso. Vale ressaltar que todas as práticas correspondentes ao conteúdo procedimental foram classificadas como "bom", porque houve a cooperação e participação dos alunos e sem eles as atividades para a realização da monografia não poderiam ocorrer. Isto se deve a vontade de aprender dos alunos e, principalmente de querer estar ali, dentro de sala de aula, buscando conhecimento.

\section{CONCLUSÕES}

Conclui-se que é possível utilizar e trabalhar os conteúdos de aprendizagem propostos por Zabala (1998). Os conteúdos de aprendizagem podem contribuir com a prática do professor auxiliando-o em sala de aula, colaborando desta forma com o processo de ensino aprendizagem dos alunos. Favorece enquanto ferramenta ao ensino de climatologia, além de ajudar o estudante a desenvolver habilidades importantes não só para a geografia, mas para a vida.

Observou-se a necessidade das escolas abordarem temas transversais e outras temáticas que gerem discussões. Intolerância religiosa deve ser assunto a ser conversado em sala de aula, para descontruir ou mesmo apresentar outras perspectivas, já que a escola é um espaço de diálogo e aprendizado.

Ao longo das atividades notaram-se dificuldades dos alunos com conteúdos relacionados às disciplinas de português e matemática, essenciais para as práticas no ensino de climatologia. A escola juntamente com os professores, deveria pensar em alternativas que visem ajudar esses alunos, por exemplo: aula de reforço, incentivo a leitura, desenvolver projetos, entre outros.

Os alunos da NEJA praticamente não são contemplados com projetos, oficinas e demais atividades pedagógicas. Deveria ser investida e criada políticas e práticas pedagógicas que contribuíssem com a melhora do ensino na Educação de Jovens e Adultos. Trabalhar com os alunos da NEJA foi de um grande aprendizado e significado. Por fim, é importante desenvolver mais projetos, pesquisas e estudos que trabalhem tanto com a Educação de Jovens e Adultos como com o ensino de climatologia. 


\section{REFERÊNCIAS}

AHRENS, A. D. Essentials of Meteorology: an invitation to the atmosphere. West Publishing Company, New York, 1993.

ANTAS, L. M. Glossário de termos técnicos. São Paulo: Traço Editora, 1979. (Coleção Aeroespacial Tomo I)

CALLAI, H. C. Aprendendo a ler o mundo: a geografia nos anos iniciais do ensino fundamental. Cad. Cedes, Campinas, v. 25, n. 66, p. 227-247, 2005.

FORTUNA, D. Climatologia geográfica e docência escolar: um relato sobre as (im)possibilidades dos recursos pedagógicos no segundo segmento do ensino fundamental. Caderno de Estudos Geoambientais CADEGEO, v.3, n.1, p.76-83, 2012.

KOVALSKI, M. L.; OBARA, A. T.; FIGUEIREDO, M. C. Diálogo dos saberes: o conhecimento científico e popular das plantas medicinais na escola. In: VIII Encontro Nacional de Pesquisa em Educação em Ciências e ICIEC Congresso Iberoamericano de Investigación en Enseñanza de las Ciencias, 2012, Campinas. VIII Encontro Nacional de Pesquisa em Educação em Ciências e ICIEC Congresso Iberoamericano de Investigación en Enseñanza de las Ciencias, 2012. Disponível em:<http://www.nutes.ufrj.br/abrapec/viiienpec/resumos/R1647-1.pdf> Acesso em: 06 de dez. de 2015.

MENDONÇA, F.; DANNI-OLIVEIRA, I. M. Climatologia: noções básicas e climas do Brasil. São Paulo: Oficina de textos, 2007.

NERVIS, D.E.; SOUZA, M.Í.A.; ALVES, A.O.S. Análise do conteúdo de climatologia em livros didáticos de geografia do $5^{\circ}$ e $6^{\circ}$ ano do ensino fundamental. Revista Geonorte, Edição Especial 2, v.1, n.5, p.45-58, 2012.

PEREIRA, T.D. Tempo de chuvas e saberes populares: um estudo sobre o ensino de climatologia na geografia escolar da Nova Educação de Jovens e Adultos. 2016. 106 p. Monografia (Licenciatura em Geografia) - Departamento de Geografia de Campos, Instituto de Ciências da Sociedade e Desenvolvimento Regional, Universidade Federal Fluminense, Campos dos Goytacazes, RJ.

SONNEMAKER, J. B. Meteorologia. 31 ${ }^{a}$ Ed. São Paulo: ASA, 2011/2012.

SOUZA, M.Í.A.; OLIVEIRA, A.O.S.A. A alfabetização climatológica: análise dos conteúdos de climatologia nos livros didáticos e preposição de novas estratégias para o ensino do clima. Revista Geonorte, Edição Especial 2, v.1, n.5, p.22-33, 2012.

VAREJÃO-SILVA, M. A. Meteorologia e climatologia. Recife: Versão digital 2, 2006.

ZABALA, A. A prática educativa: como ensinar. Porto Alegre: Artmed, 1998. 